DOE/MC/31388 -. 5775

(DE97005473)

\title{
Task 9 - Centrifugal Membrane Filtration
}

\author{
Semi-Annual Report \\ November 1, 1996 - March 31, 1997
}

\author{
By: \\ Daniel J. Stephan \\ Michael E. Grafsgaard
}

Work Performed Under Contract No.: DE-FC21-94MC31388

For

U.S. Department of Energy

Office of Environmental Management

Office of Technology Development

1000 Independence Avenue

Washington, DC 20585

19980313078
U.S. Department of Energy

Office of Fossil Energy

Federal Energy Technology Center

Morgantown Site

P.O. Box 880

Morgantown, West Virginia 26507-0880

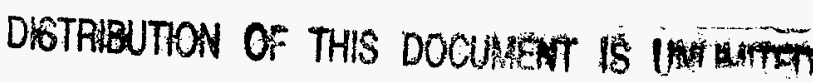

By

Energy \& Environmental Research Center

University Of North Dakota

P.O. Box 9018

Grand Forks, North Dakota 58202-9018

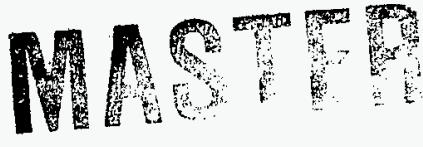

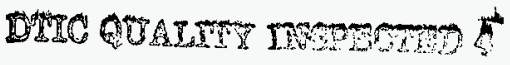




\section{Disclaimer}

This report was prepared as an account of work sponsored by an agency of the United States Government. Neither the United States Government nor any agency thereof, nor any of their employees, makes any warranty, express or implied, or assumes any legal liability or responsibility for the accuracy, completeness, or usefulness of any information, apparatus, product, or process disclosed, or represents that its use would not infringe privately owned rights. Reference herein to any specific commercial product, process, or service by trade name, trademark, manufacturer, or otherwise does not necessarily constitute or imply its endorsement, recommendation, or favoring by the United States Government or any agency thereof. The views and opinions of authors expressed herein do not necessarily state or reflect those of the United States Government or any agency thereof. 


\section{DISCLAIMER}

This report was prepared as an account of work sponsored by an agency of the United States Government. Neither the United States Government, nor any agency thereof, nor any of their employees makes any warranty, express or implied, or assumes any legal liability or responsibility for the accuracy, completeness, or usefulness of any information, apparatus, product, or process disclosed or represents that its use would not infringe privately owned rights. Reference herein to any specific commercial product, process, or service by trade name, trademark, manufacturer, or otherwise does not necessarily constitute or imply its endorsement, recommendation, or favoring by the United States Government or any agency thereof. The views and opinions of authors expressed herein do not necessarily state or reflect those of the United States Government or any agency thereof.

\section{EERC DISCLAMMER}

LEGAL NOTICE This research report was prepared by the Energy \& Environmental Research Center (EERC), an agency of the University of North Dakota, as an account of work sponsored by U.S. Department of Energy (DOE) Federal Energy Technology Center. Because of the research nature of the work performed, neither the EERC nor any of its employees makes any warranty, express or implied, or assumes any legal liability or responsibility for the accuracy, completeness, or usefulness of any information, apparatus, product, or process disclosed, or represents that its use would not infringe privately owned rights. Reference herein to any specific commercial product, process, or service by trade, trademark, manufacturer, or otherwise does not necessarily constitute or imply its endorsement or recommendation by the EERC.

\section{ACKNOWLEDGMENT}

This semiannual report was prepared with the support of the DOE Federal Energy Technology Center Cooperative Agreement No. DE-FC21-94MC31388. However, any opinions, findings, conclusions, or recommendations expressed herein are those of the author(s) and do not necessarily reflect the views of the DOE. 


\section{TABLE OF CONTENTS}

LIST OF FIGURES $\ldots \ldots \ldots \ldots \ldots \ldots \ldots \ldots \ldots \ldots \ldots \ldots \ldots \ldots \ldots \ldots$

LIST OF TABLES $\ldots \ldots \ldots \ldots \ldots \ldots \ldots \ldots \ldots \ldots \ldots \ldots \ldots \ldots \ldots \ldots \ldots$

1.0 BACKGROUND $\ldots \ldots \ldots \ldots \ldots \ldots \ldots \ldots \ldots \ldots \ldots \ldots \ldots \ldots \ldots \ldots \ldots \ldots$

2.0 OBJECTIVES $\ldots \ldots \ldots \ldots \ldots \ldots \ldots \ldots \ldots \ldots \ldots \ldots \ldots \ldots \ldots \ldots \ldots \ldots \ldots \ldots$

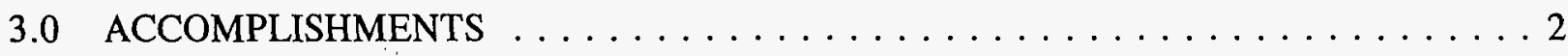

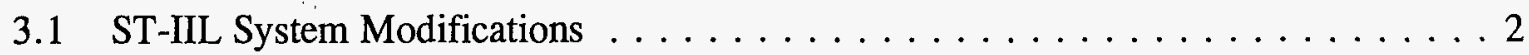

3.2 Alternative Turbulence Promoter Development . . . . . . . . . . . . 2

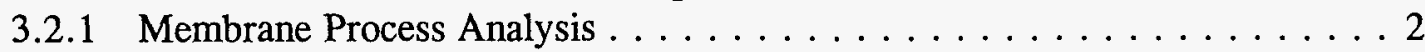

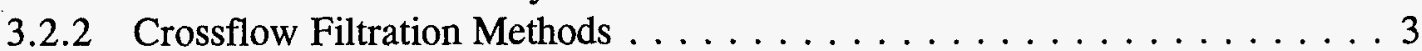

3.2.3 Turbulence Promoter Design $\ldots \ldots \ldots \ldots \ldots \ldots \ldots \ldots$

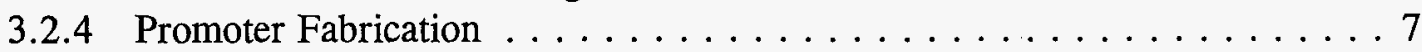

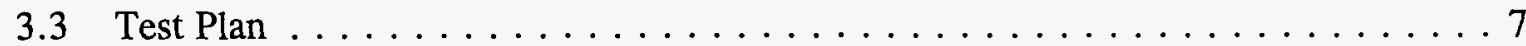

4.0 FUTURE WORK $\ldots \ldots \ldots \ldots \ldots \ldots \ldots \ldots \ldots \ldots \ldots \ldots \ldots$

$5.0 \quad$ REFERENCES $\ldots \ldots \ldots \ldots \ldots \ldots \ldots \ldots \ldots \ldots \ldots \ldots \ldots \ldots \ldots \ldots \ldots \ldots$

\section{LIST OF FIGURES}

1 Current turbulence promoter $\ldots \ldots \ldots \ldots \ldots \ldots \ldots \ldots \ldots \ldots \ldots \ldots \ldots \ldots \ldots \ldots$

2 Angled-blade turbulence promoter $\ldots \ldots \ldots \ldots \ldots \ldots \ldots \ldots \ldots \ldots \ldots \ldots \ldots \ldots \ldots$

\section{LIST OF TABLES}

1 Statistical Test Matrix for Each Turbulence Promoter $\ldots \ldots \ldots \ldots \ldots \ldots \ldots$ 


\section{CENTRIFUGAL MEMBRANE FILTRATION}

\subsection{BACKGROUND}

This project is designed to establish the utility of a novel centrifugal membrane filtration technology for the remediation of liquid mixed waste streams at U.S. Department of Energy (DOE) facilities in support of the DOE Environmental Management (EM) program. The Energy \& Environmental Research Center (EERC) has teamed with SpinTek Membrane Systems, Inc., a small business and owner of the novel centrifugal membrane filtration technology, to establish the applicability of the technology to DOE site remediation and the commercial viability of the technology for liquid mixed waste stream remediation.

The technology is a uniquely configured process that makes use of ultrafiltration and centrifugal force to separate suspended and dissolved solids from liquid waste streams, producing a filtered water stream and a low-volume contaminated concentrate stream. This technology has the potential for effective and efficient waste volume minimization, the treatment of liquid tank wastes, the remediation of contaminated groundwater plumes, and the treatment of secondary liquid waste streams from other remediation processes, as well as the liquid waste stream generated during decontamination and decommissioning activities.

\subsection{OBJECTIVES}

The overall project consists of several integrated research phases related to the applicability, continued development, demonstration, and commercialization of the SpinTek centrifugal membrane filtration process. This phase of work is a continuation of the Phase 1 evaluation of the SpinTek centrifugal membrane filtration technology. During Phase 1 testing conducted at the EERC using the SpinTek ST-IIL unit operating on a surrogate tank waste, a solids cake developed on the membrane surface. Solids cake development was observed where linear membrane velocities were less than 17.5 feet per second and resulted in a reduction of unobstructed membrane surface area of up to $25 \%$, reducing overall filtration performance.

The primary goal of the Phase 2 research effort is to enhance filtration performance through the development and testing of alternative designs of the turbulence promoters to generate a shear force across the entire membrane surface that is sufficient to maintain a self-cleaning membrane capability and improve filtration efficiency and long-term performance. Specific Phase 2 research activities include the following:

- System modifications to accommodate an 11-inch-diameter, two-disk rotating membrane assembly

- Development and fabrication of alternative designs to the existing turbulence promoters

- Testing and evaluation of the existing and alternative turbulence promoters under selected operating conditions using a statistically designed test matrix 
- Data reduction and analysis

\subsection{ACCOMPLISHMENTS}

Major project activities during this reporting period include system modifications to the STIIL centrifugal membrane filtration unit, the design of alternative turbulence promoters, and the development of a statistical matrix testing plan.

\subsection{ST-IIL System Modifications}

The Phase 1 testing and process evaluation were conducted using a single rotating disk with a diameter of 8 inches and membranes mounted on both sides of the disk. The total membrane surface area of the 8-inch unit was $0.5 \mathrm{ft}^{2}$. Stationary turbulence promoters were located one on each side of a rotating membrane disk within a pressure housing.

Phase 2 testing will be conducted using an 11-inch-diameter, two-disk system. This system has a total membrane surface area of $2.0 \mathrm{ft}^{2}$. Membranes are mounted on both sides of each of the rotating disks. The two-disk system has three stationary turbulence promoters, one mounted between the rotating membrane disks and the other two on the outside of the respective membranes.

SpinTek had the new 11-inch rotating assembly fabricated and shipped to the EERC. The new rotating assembly was installed on the ST-IIL test unit.

\subsection{Alternative Turbulence Promoter Development}

Activities on the development of alternative turbulence promoters include membrane process analysis, a review of crossflow filtration methods, turbulence promoter design, and turbulence promoter fabrication.

\subsubsection{Membrane Process Analysis}

During the Phase 1 testing, a solids cake developed on the central portion of the membrane surface. Although the cake buildup encompassed only about $25 \%$ of the total area, its location can be expected to have had a pronounced effect on the flux, since the highest transmembrane pressure (the net filtration driving force) occurs at the membrane center. Transmembrane pressure varies over the surface because of the membrane's rotation, which creates centrifugal forces resulting in an uneven pressure distribution.

Minimization of filter cake deposition is essential for the success of this type of filtration system. Crossflow filtration processes were studied to gather information that could indicate potential methods for reducing solids cake buildup. Crossflow, or tangential flow, filtration involves moving a fluid tangentially to a filter while simultaneously filtering it. The tangential flow creates a force parallel to the membrane that helps to wash filtered particles away, thereby keeping the filter clean and the permeate flux high. Opposing the shear generated by the crossflow is the drag force caused by water passing over the filtrate and through the membrane. The higher the flux, the faster the perpendicular flow to the membrane and the stronger the drag force. Particles 
become deposited on the filter when the drag forces acting upon them become higher than the shear force pulling them away. Once it is deposited, the shear required to remove the particulate must overcome the drag force as well as the friction force holding it to the filter. Thus, utilizing techniques to prohibit initial particle deposition would seem to be the most efficient method of membrane cleaning.

Particles deposited on the filter soon form a gel or filter cake layer that can be several magnitudes lower in permeability than the original filter, restricting the flow through it (1). This restriction results in a decrease in flux and its associated drag force. Eventually, an equilibrium occurs between the crossflow and the drag forces. The thickness and permeability of the gel layer when this equilibrium occurs determines the steady-state flux of the filter.

The formation of a small cake layer is almost certain in any filtration process, so it is advantageous to utilize its properties to enhance filtration. The layer can provide a barrier between the shear force and filter, protecting it from wear. It can also improve filtration by acting as a prefilter before the fluid passes through the membrane. Filtration methods should be developed to take advantage of any benefits that a gel layer may have in any crossflow application.

\subsubsection{Crossflow Filtration Methods}

The means of developing the shear force required to remove particulate from the membrane surface can be divided into two categories: low-shear crossflow filtration and high-shear crossflow filtration (2). Low-shear methods use flow velocity as the mechanism for solids cake reduction. The shear required to keep the particles suspended is a function of the feed stream pumping rate. Flow velocity downstream of the feed inlet can be reduced because of the removal of permeate as the feed passes across the membrane. The available shear is lowest near the edge of the membrane, while the solids concentration is the highest at that point due to the removal of the permeate. Lowshear methods therefore employ large pumping rates and high recirculation ratios.

The shear force in low-shear crossflow filters can be increased by utilizing unsteadiness in the crossflow. Crossflow instabilities can be a result of 1) roughness, where protuberances are placed on or near the filter surface; 2) flow pulsations in the feed stream; and 3) secondary flows where filter geometry is chosen to help generate Taylor and Dean vortices (3). Experiments using these methods have shown increased flux and efficiency in low-shear systems.

Though the low-shear technique works well in many applications of waste treatment, it becomes ineffective for wastes containing a high percentage of solids. The high solids content overwhelms the membrane, clogging the flow passages and rendering the membrane useless. In cases such as this, high-shear filtration methods should be used. These types of systems utilize a different technique for creating shear and are designed to operate under high solids loadings. Instead of relying on high feed stream velocities to promote shear, mechanical methods are used, including moving the filter relative to the fluid (as with SpinTek) or imparting velocity to the feed water in close proximity to the filter by spinning disks or other mechanical devices. Whichever shear-promoting means chosen, the result tends to be a much more effective filter cleaning. Since the energy is applied in the direct vicinity of the membrane, little is wasted on fluid farther away from it. 


\subsubsection{Turbulence Promoter Design}

Analysis of flow patterns within the filter chamber was used to develop alternative turbulence promoter designs. The complex nature of flow within the chamber made a complete detailed analysis impractical. However, a basis for describing typical flows with the filtration chamber was found by utilizing research done on flow boundaries next to rotating disks.

Experiments have shown the velocity of a fluid within a filter chamber containing a smooth, grooveless disk (in our case the spinning filter) to comprise three regions: a boundary layer of thickness $\delta$ next to the spinning disk, a boundary layer of thickness $\zeta$ next to a fixed plate, and a core region between the two boundary layers. Suggestions for equations identifying flow velocity estimation within each of the layers for both laminar $\left(\operatorname{Re} \leq 3 \times 10^{5}\right)$ and turbulent flow $(\operatorname{Re} \geq 3 \times$ $10^{5}$ ) where $\operatorname{Re}=r_{0} 2 \omega / \nu$ have been proposed (4).

Flows normally encountered with high-shear dynamic filtration tend to be turbulent $(2,5)$, due to the high energy transfer from disk to fluid. An approximation for the flow patterns of a smooth spinning disk under turbulent flow conditions was analyzed by the following equations (4):

Fixed plate boundary layer:

$$
\begin{aligned}
& \text { Boundary layer thickness }(\zeta)=0.309\left\{\mathrm{r}(1-\mathrm{K})^{3} / \mathrm{K}\right\}\left(\nu / \mathrm{r}^{2} \omega_{0}\right)^{1 / 5} \\
& \text { Tangential velocity }(\mu)=\mathrm{Kr} \varpi_{0}(\mathrm{~s} / \zeta)^{1 / 7} \\
& \text { Radial velocity }(\mathrm{u})=-0.374 \mathrm{Kr} \omega_{0}(\mathrm{~s} / \zeta)^{1 / 7}(1-\mathrm{s} / \zeta)
\end{aligned}
$$

Spinning disk boundary layer:

$$
\begin{aligned}
& \text { Boundary Layer Thickness }(\delta)=0.526(1-\mathrm{K})^{2} \mathrm{r}\left(\nu / \mathrm{r}^{2} \omega_{0}\right)^{1 / 5} \\
& \text { Tangential Velocity }(\mu)=\mathrm{r} \omega_{0}\left\{1-(\mathrm{z} / \delta)^{1 / 7}+\mathrm{K}(\mathrm{z} / \delta)^{1 / 7}\right\} \\
& \text { Radial Velocity }(\mathrm{v})=0.220(1-\mathrm{K}) \mathrm{r} \omega_{\mathrm{o}}(\mathrm{z} / \delta)^{1 / 7}(1-\mathrm{z} / \delta)
\end{aligned}
$$

Where:

$\mathrm{K}=\mu / \mathrm{r} \varpi$ is the ratio of tangential velocities in the core and on the spinning disk, approximately 0.4 to 0.5 for a smooth disk.

$\omega_{\mathrm{o}}=$ the angular velocity of the disk.

$v=$ the kinematic velocity of the fluid.

$\mathrm{z}=$ the axial distance from the spinning disk.

$r=$ the radial distance from the center of the disk. 
Equations 1-6 were used to identify methods that could be used to enhance the flow patterns within the filter chamber, to increase both circulation and shear. Assuming the turbulence promoter to be the stationary plate, one could expect turbulent flow at much lower Reynolds numbers because of the effects of the promoter blades.

To reduce cake deposition on the membrane, the disk boundary layer thickness should be kept to a minimum. This eliminates the chance for particles to be trapped within it by the permeate flux drag force. Reducing the boundary layer size while increasing both the tangential and radial velocities of the fluid next to the disk should result in a sweeping action within the chamber that extracts particles before they are deposited on the membrane.

Experiments performed on spinning grooved disks have shown that the grooving increases the tangential and radial velocities on fluids next to them (4). The velocity increases were thought to be caused by the increased friction between the disk and fluid brought about by the grooves. Radial flow along the grooves was thought to be the cause of the increased radial velocities. Assuming the tractive force can be created by blades as well as grooves, placement of blades directly on the spinning filter disk may also help reduce filter cake buildup. Although blades on the filter disk may slightly decrease membrane area, the area lost would be small, since only a few blades should be required. To be effective, however, stationary membrane filter disks would have to replace the current turbulence promoters. The spinning filter with blades could be used to impart the shear necessary to keep the stationary filter free of deposits while increasing fluid circulation within the entire filter chamber. Drawbacks of this design could include a net decrease in shear along the membrane due to the blades increasing the amount of fluid spinning with the disk. Power consumption would be increased, as more energy is being imparted to the fluid. Finally, some system modifications would be required for such a design.

Reducing the boundary layer thickness may also be accomplished by reducing the clearance between the membrane and promoter. Though varying the clearance for filtration units with rotating shear promoters and stationary filter disks has shown little flux changes for small clearance adjustments, no evidence of the same occurrence for rotating filter disks was found. Experiments on rotating disks showed increased local shear stresses with decreased clearance for various operating conditions (2). The stress increase should result in less particle deposition and a higher flux. The increased stress may increase power consumption, but may be required only within the inner portion of the membrane where lower local velocities and highest permeation drag forces are present. The practical limit of clearance reduction is unknown, but adequate clearance must be maintained to prevent membrane-promoter contact during operation.

The current turbulence promoter, pictured in Figure 1, looks to be well-suited for creating shear along the membrane. The stationary blades increase velocity gradients and turbulence along the membrane, resulting in a decreased solids cake. However, although turbulence and shear are high, the circulation of fluid in and out of the disks may be small. Assuming the primary flow patterns are outward fluid flow along the spinning membrane and feed inflow along the stationary blades (6), this configuration may not be provide enough circulation for solutions with a high solids content. Low circulation may cause excessive solids concentrations within the filter disks, resulting in filter cake formation.

Incorporating a promoter design that increases flow circulation within the chamber may also help decrease gel layer formation. A promoter having angled blades, such as the one pictured in Figure 2, should help increase fluid circulation within the chamber. This type of design could help 


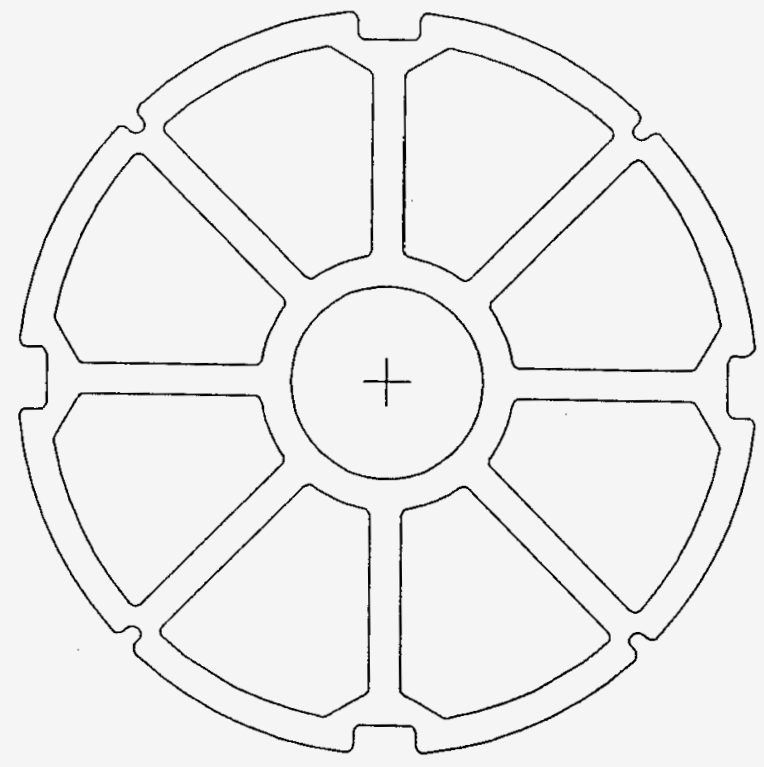

Figure 1. Current turbulence promoter.

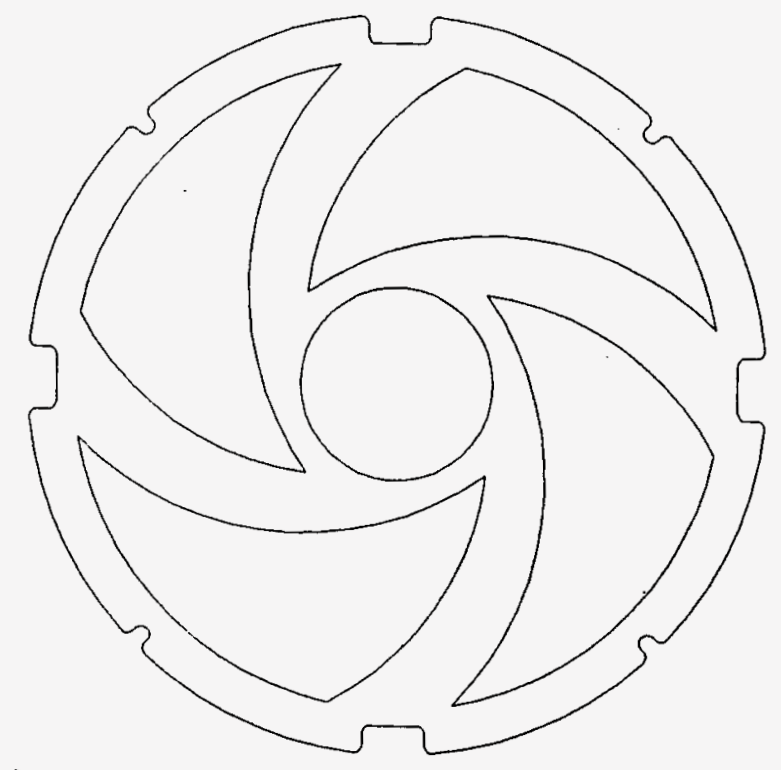

Figure 2. Angled-blade turbulence promoter. 
to remove particles from within the filtration disks by imparting a radial velocity to fluid particles having a tangential velocity component. The radial velocity increase could help expel particles from the central portion of the membrane, while helping bring fresh waste to the disks for filtration.

Creating a bevel on the leading edge of the turbulence promoter blades may also be useful in limiting filter cake buildup. Beveling the edge, alternately on top, then bottom, for consecutive blades may allow the blade to create lift and turbulence to help increase shear and reduce the solids cake. The beveling effect may not be pronounced on the original promoter design, but using thicker promoters with a smaller membrane-promoter gap may magnify the beveling effect.

\subsubsection{Promoter Fabrication}

A new promoter design was created utilizing a CAD drawing of a current turbulence promoter. Use of the current drawing ensured a proper fit within the unit, decreasing the chance of equipment damage. The new promoters have yet to fabricated, but will be cut from stainless steel with a computer-guided plasma cutter. A newly designed promoter set of a thickness equal to the current design will be created to test design efficiency. Other promoter sets will be constructed of different thicknesses for both the original and new designs. Modifications of the original sets may be used in later trials to test various aspects of promoter design.

\subsection{Test Plan}

The Phase 1 testing and evaluation considered the effects of four operating variables to define system operation: temperature, pressure, membrane rotational speed, and solids loading. Phase 2 testing will consider the two variables that have the greatest influence on membrane shear forces and solids cake development: pressure and membrane rotational speed. Temperature and solids loading will be held constant. The operating temperature will be maintained at $100^{\circ} \mathrm{F}$. A calcium carbonate suspension will be prepared to simulate a $20 \mathrm{wt} \%$ solids loading. A statistical matrix test design was developed to evaluate the effects of pressure, rotational speed, and time on filtration performance using six different turbulence promoter designs. The design consists of high $(+)$ and low (-) values for pressure and rotational speed, with the overall run time being monitored and recorded. Table 1 summarizes the general test conditions for each turbulence promoter. The run order will be randomized prior to testing. Duplicate runs will also be conducted to evaluate precision and potential membrane deterioration.

TABLE 1

Statistical Test Matrix for Each Turbulence Promoter

\begin{tabular}{ccc}
\hline Run & Pressure, psig & Rotor Speed, rpm \\
\hline 1 & + & + \\
2 & + & - \\
3 & - & - \\
4 & - & + \\
\hline
\end{tabular}




\subsection{FUTURE WORK}

Continued work on the project will include fabrication, testing, and evaluation of each of the turbulence promoters, data reduction and analysis, systems engineering, and reporting.

\subsection{REFERENCES}

1. Jiao, D.; Sharma, M.M. "Mechanism of Cake Buildup in Crossflow Filtration of Colloidal Suspensions," Journal of Colloid and Interface Science 1994, 162, 454-462.

2. Murkes, J.; Carlsson, C.G. Crossflow Filtration; John Wiley \& Sons Ltd., 1988.

3. Mackley, M.R., Sherman, N.E. "Cross-Flow Filtration with and Without Cake Formation," Chemical Engineering Science 1994, 49, 171-178.

4. Shirato, M.; Murase, T.; Yamazaki, H.; Iwata, M.; Inayoshi, M. "Patterns of Flow in a Filter Chamber During Dynamic Filtration with a Grooved Disk," International Chem. Eng. 1987, 27, 304-310.

5. Wronski, S.; Molga, E.; Rudniak, L. "Dynamic Filtration in Biotechnology," Bioprocess Engineering 1989, 4, 99-104.

6. Lee, S.S.; Burt, A.; Russotti, G.; Buckland, B. "Microfiltration of Recombinant Yeast Cells Using Rotating Disk Dynamic Filtration System,"Biotechnology and Bioengineering 1995, 48, $386-400$. 
M97005473

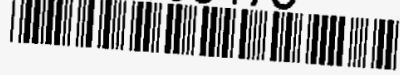

Report Number (14) DOE/MC/31388- 5775

دubl. Date (11) 199710

sponsor Code (18) DOE/EM, XF

IC Category (19) $4 C-2000, D O E / E R$

DOE 